\title{
MORFOLOGIA URBANA E A (IR)REGULARIDADE FUNDIÁRIA: UMA ABORDAGEM NO SEMIÁRIDO NORDESTINO
}

Urban morphology and land irregularity: an approach in semi-arid northeast

\author{
Daniela de Freitas Lima ${ }^{1}$, Almir Mariano de Sousa Junior ${ }^{2}$, Manoel Mariano Neto \\ da Silva ${ }^{3}$ e Carla Caroline Alves Carvalho ${ }^{4}$ \\ 1, 3, 4Estudante de Bacharelado em Ciência e Tecnologia, Universidade Federal Rural do Semi-Árido \\ (UFERSA), Pau dos Ferros, RN, Brasil \\ ${ }^{2}$ Professor Mestre da Universidade Federal Rural do Semi-Árido (UFERSA), Pau dos Ferros, RN, Brasil
}

\begin{abstract}
Resumo
O crescimento urbano desordenado decorrente da falta de planejamento e estruturação do espaço geográfico dá origem ao processo de formação de periferias e a ocupação imprópria de assentamentos. As cidades brasileiras estão marcadas pela desigualdade social: enquanto uns vivem em lugares altamente privilegiados, outros residem em bairros com condições de habitação e saneamento decadentes. O objetivo deste artigo é descrever os problemas decorrentes do crescimento e ocupação urbana desordenada no Brasil e a situação de cinco municípios do Semiárido Potiguar no âmbito de (ir)regularidade fundiária. Foi estudada a realidade habitacional de cidades brasileiras, observando-se os contrastes existentes entre os espaços ocupacionais que foram planejados e aqueles que se constituíram de forma indevida e analisados cinco municípios do alto oeste potiguar, especificamente no quesito regularização fundiária. Verifica-se que há uma divisão do espaço urbano do Brasil em regiões com excelente infraestrutura disponível aos seus ocupantes e locais com a ausência de condições mínimas de dignidade, além de um alto índice de irregularidade dominial. Porém, é possível fazer uma reestruturação urbana por meio de programas que visem a regularização fundiária e a, consequente, reformulação das cidades.
\end{abstract}

Palavras-chave: Planejamento urbano. Reformulação das cidades. Regularização fundiária.

\begin{abstract}
The urban growth disordered due to lack of planning and structuring of geographical space gives rise to the outskirts of the training process and improper occupation of settlements. Brazilian cities are marked by social inequality: while some live in highly privileged places, others reside in neighborhoods with housing and sanitation decadent. The purpose of this article is to describe the problems of growth and unplanned urban settlements in Brazil and the situation of five cities in the semiarid potiguar land irregularity. The housing reality of Brazilian cities was studied, observing the conflicts between occupational areas that were planned and those that formed improperly and analyzed five municipalities of the semiarid northeast, specifically in the category land regularization. It appears that there is a division of the urban space of Brazil in regions with excellent infrastructure available to its occupants and local with the absence of minimum conditions of dignity, and a high dominial irregularity index. However, you can do an urban restructuring through programs aimed at land tenure and the consequent redesign of cities.
\end{abstract}

Keywords: Urban planning. Reformulation of cities. Land regularization. 


\section{Introdução}

O índice de crescimento anual do Brasil quarenta anos antes da década de 80 (oitenta) foi objeto de esperança de vida melhor para muitas pessoas. Além disso, o desenvolvimento de tecnologias no âmbito agropecuário a partir da industrialização, o que dispensa grande parte da mão de obra braçal e deixa produtores de pequeno porte com baixo rendimento, foi motivo de buscar alternativas nas cidades. Foi nesta perspectiva que a população urbana brasileira cresceu exacerbadamente.

Com isso, houve um superpovoamento nas cidades, que provocou ocupação dos espaços de forma desordenada, resultando inúmeros problemas sociais, econômicos e ambientais. A aglomeração de moradores sem condições financeiras em bairros pobres foi uma situação característica decorrente do inchaço urbano. $\mathrm{O}$ espaço foi sendo fragmentado em bairros com excelente infraestrutura e alta especulação imobiliária, e locais em que o saneamento, saúde e educação são precários ou mesmo inexistentes.

Sem possibilidade de escolhas de habitação, muitos acabam invadindo áreas de risco ou preservação permanente. Há uma "disputa" entre natureza e cidade, uma vez que os espaços que deveriam ser poupados tornam-se ocupados por indivíduos que são impossibilitados pela capacidade financeira de adquirir espaço devidamente destinado à moradia. Essas ocupações também se dão sem nenhum tipo de legalidade em terrenos que não estão sendo utilizados para fins socioeconômicos há anos, mas que possuem proprietários.

Assim, por serem de um dono ou terem o direito de serem deixados intactos, os assentamentos territoriais ilegais ou invasivos estão sujeitos à destituição. A remoção das famílias ali existentes quase sempre se dá de forma violenta e as deixam em situações piores do que se encontravam, pois essas pessoas construíram um patrimônio, por menor que seja, ao longo do tempo que estiveram residindo neste local, e saem apenas com a roupa que estão vestindo no momento da desapropriação, perdendo tudo que edificaram ao longo de suas vidas. Muitos perdem seus empregos por serem vistos como "marginais" ao se apropriar de bens de outros e recebem auxílios ínfimos para locar residências que não condizem com a realidade de sua família, visto que geralmente a verba disponibilizada pelas prefeituras para realocação de famílias não é destinada de acordo com análises familiares e, consequentemente, não é suficiente para pagar o aluguel de casas com condições de moradia para uma família que tem 10 integrantes, por exemplo.

A própria Constituição Brasileira prevê o direito à moradia e a desapropriação de terras que não possuem finalidade social para que ocorra sua redistribuição. Mas, esses decretos são negligenciados. Segundo o censo 2010 do Instituto Brasileiro de Geografia e Estatística - IBGE, o número de domicílios vagos no Brasil é 6,1 milhões. Essa estatística supera a quantidade de moradias que deveriam ser edificadas para abrigar as famílias brasileiras que não tem teto ou vivem em locais impróprios.

Assim, é responsabilidade dos municípios realizarem a regularização fundiária dos assentamentos caracterizados como área de interesse social no intuito de buscar fazer a reformulação das cidades, dando direito de posse a populações residentes nessas áreas e proporcionando aos moradores a possibilidade de cobrar melhorias em saneamento, iluminação, educação e demais benefícios que uma cidade pode oferecer.

É importante salientar que áreas que não possuem regularização fundiária, não podem participar de programas de financiamento de crédito para reforma e edificação de moradias, que poderiam auxiliar na adequação de habitações em locais apropriados para ocupação. Mas com a titulação de suas terras é possível além de adquirir financiamento, realizar tramites de transferência de posse e ter acesso a ambientes realmente urbanizados.

Grande parte das famílias que possuem condições de habitabilidade críticas está na região Nordeste. Conforme o IBGE (2011) essa região ocupa o segundo lugar do ranking de aglomerados subnormais do Brasil, ficando atrás apenas do Sudeste. Esse aspecto merece atenção e ação por parte dos municípios na luta pela reformulação urbana.

Nesta perspectiva, este artigo apresenta aos problemas da realidade brasileira decorrentes dos aspectos de ocupação urbana desordenada. O intuito é descrever como a falta de planejamento da 
urbanização influencia na organização dos espaços das cidades do Brasil e apresentar o alto índice de irregularidade dominial presente nos municípios, especialmente em municípios do alto oeste do Rio Grande do Norte.

O texto aborda caracterização dos espaços urbanos, dando ênfase às periferias e centros com alta infraestrutura, apresenta a realidade periférica brasileira e políticas de regularização fundiária, mostra a situação de registros imobiliários de algumas cidades do semiárido nordestino e apresenta a proposta de regularização através da parceria com a universidade.

\section{$2 \mathrm{O}$ contraste dos espaços urbanos}

No Brasil, o quadro habitacional urbano nos anos 60 era bem diferente do atual, pois a maior parte da população estava concentrada em áreas rurais, aproximadamente $55 \%$ das pessoas estavam no campo. Essa situação se reverteu totalmente até alcançar a realidade ocupacional de hoje.

A mudança do cenário populacional brasileiro desde a década de 80 é perceptível e foi se tornando mais intensa. Enquanto a massa urbana crescia, a rural ia sendo reduzida na mesma proporção. As cidades foram se tornando fermentadas de pessoas ao mesmo tempo em que o campo se via cada vez mais vazio. Segundo o IBGE (2011) a distribuição da população por domicílio passou por uma forte transformação nos últimos quarenta anos, conforme mostra a figura 1.

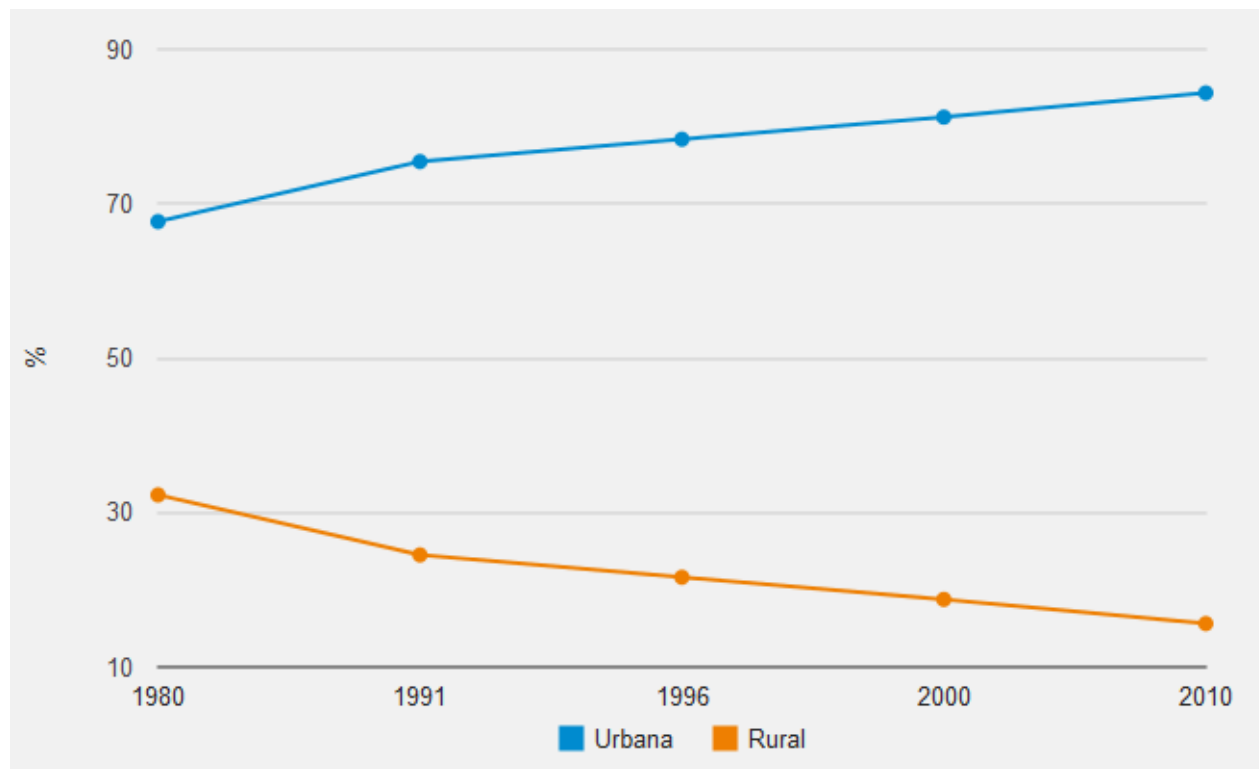

Figura 1 - Distribuição da população Brasileira entre os anos de 1980 e 2010. Fonte: IBGE (2011).

A população por domicílio nas cidades no Brasil passou de 67,70 \% no ano de 1980 para 84,36 \% em 2010, ou seja, em quatro décadas, o crescimento populacional urbano foi de aproximadamente $17 \%$. Já a população rural foi de $32,30 \%$ para $15,64 \%$ no mesmo período das mudanças urbanas.

Dentre os motivos para que acontecesse a concretização desses eventos podemos citar: a busca por melhores condições de vida através da obtenção de um emprego nas cidades e o baixo rendimento dos pequenos produtores frente às altas tecnologias que os fazendeiros de grande porte poderiam utilizar.

Em virtude da atratividade urbana despertada em vários indivíduos, as cidades foram acomodando uma massa populacional muito grande sem que houvesse nenhum tipo de planejamento para receptividade dessas pessoas, gerando muitos impactos negativos para a sociedade, visto que enquanto os que tinham condições financeiras acomodavam-se em locais agradáveis e confortáveis de viver, aqueles que encontraram uma realidade diferente da que imaginavam, continuando com baixo poder aquisitivo, se instalavam em ambientes sem condições sanitárias e de infraestrutura aptos à habitação. 
Conforme Maricato (2013), grande parte das cidades é construída pelos moradores em áreas invadidas, muitas delas ambientalmente frágeis ou de loteamentos ilegais.

Sem alternativas de obter propriedades devidamente regulamentadas, adquirir de forma clandestina ou invadir áreas para utilizar para fim de moradia foi uma prática adotada por parte da população. Esses assentamentos constituem em grande parte Áreas de Preservação Permanente (APP's), Áreas de Risco ou mesmo propriedade privada ocupada sem nenhum tipo de legalidade por aqueles que buscam um local para habitar.

São fatores como esses que dividiram as cidades brasileiras em núcleos urbanizados evoluídos e parcelas fragilizadas decadentes. Bairros em que residem cidadãos financeiramente estruturados são marcados pela qualidade na localização das casas, no saneamento básico, na educação, na saúde e na segurança. Em contrapartida, os assentamentos subnormais (como são denominadas as favelas pelo IBGE) carecem de serviços básicos de urbanização como: sistema sanitário, pavimentação, água potável e iluminação pública.

Para tornar mais claro, podemos citar a cidade do Rio de Janeiro, que detém o preço mais caro do metro quadrado do Brasil, segundo a Fundação Instituto de Pesquisas Econômicas - Fipe (2014), mas que apresenta uma extrema desigualdade econômica, pois enquanto bairros como Leblon e Ipanema tem preço médio de metro quadrado superior a vinte mil reais, conforme mostra resultados de pesquisas feitas pelo Sindicato de Habitação do Rio - Secovi-Rio (2014), as favelas como Rocinha e Cidade de Deus não possuem nenhum tipo de reconhecimento imobiliário, uma vez que são totalmente destituídos de condições urbanísticas.

É através desta realidade que se tornam perceptíveis as desigualdades que acometem parte da população nos âmbitos sociais, em que os ocupantes das periferias não têm oportunidades empregatícias e educacionais, pois empresas geralmente não estão instaladas nestes locais e escolas, quando existem, não apresentam qualidade de ensino; econômicos, já que por não estarem inseridas socialmente tornam-se incapacitadas de participar ativamente da economia do país ao realizar aquisição de produtos para uso e consumo próprio; ambientais, porque estão vulneráveis à desmoronamento de casas inseguras, inundações e doenças causadas por proliferação de insetos no envolto das residências periféricas.

\section{0 cenário brasileiro na disparidade urbana}

De acordo com o IBGE (2011) existem 6.329 assentamentos subnormais no Brasil, e as regiões que mais acometidas por essas áreas são Sudeste e Nordeste. Esta última abriga 28,7\% dos domicílios em aglomerados subnormais e fica em segundo lugar no ranking das regiões do Brasil com o maior número de favelas.

Os assentamentos subnormais tratados estatisticamente aqui são conceituados pelo IBGE (2011) como conjunto constituído por 51 ou mais unidades habitacionais desprovidas de título de propriedade ou que apresente irregularidade das vias de circulação, tamanho e forma dos lotes, e sejam carentes de serviços públicos essenciais como coleta de lixo, rede de esgoto, rede de água, energia elétrica e iluminação pública.

Com o aumento crescente da especulação imobiliária, torna-se cada vez mais difícil adquirir uma casa própria regular ou mesmo locar uma residência em centros urbanos com condições infraestruturais adequadas para habitação. Assim, parte da população vai sendo expulsa para locais distantes dos postos de trabalho, aumentando seus custos de locomoção, em um trânsito caótico, sendo instalados em comunidades com poucas unidades de saúde e até sendo taxados como "marginais" por conviver com pessoas obrigadas a cometer atrocidades em busca da sobrevivência.

Fatores como estes mostram que apesar dos avanços tecnológicos e dos programas de apoio financeiro desenvolvidos pelo governo, a desigualdade social presente nas cidades brasileiras é marcante. As cidades, globalizadas, não apenas do Brasil, mas também de outros países carregam mazelas das diferenças: 
A globalização e a guinada em direção ao neoliberalismo enfatizaram, ao invés de diminuir, as desigualdades sociais. [...] Os resultados foram indelevelmente gravados nas formas espaciais de nossas cidades, que cada vez mais tornam-se cidades "de fragmentos fortificados". (Maricato, E. et al., 2013, p. 28-29)

Por estarem alojados em áreas privadas, do poder público, ambientalmente preservadas ou de segurança condenável, famílias que residem em assentamentos irregulares estão sujeitas à remoções forçadas, que frequentemente acontecem de forma violenta, sem oportunidade de busca de outro local para moradia ou guarda de pertences. Isso deixa a população desses ambientes mais vulneráveis do que se encontravam, pois até então apresentavam uma condição "estável" e foram surpreendidos por órgãos públicos e até mesmo por ações policiais.

Os subsídios municipais para o remanejamento das famílias para outras residências na maioria das vezes são insuficientes para ocupar bairros adequados para habitação e é necessário utilizar parte do orçamento destinado a outras obrigações para complementar o valor da locação. Além disso, as remoções de assentamentos irregulares são acompanhadas pela mídia e ao serem vistos ou ouvidos em reportagens sobre as desapropriações, cidadãos estão propícios a perderem seus empregos por serem vistos como infratores da lei, ficando em situações de desespero.

A Constituição Brasileira de 1988 garante o direito à moradia à população no artigo 6º e institui a utilização das extensões territoriais para fins sociais de acordo com as especificações de plano diretor no artigo 182, sob pena de desapropriação, no intuito de que todos possam está seguros e estáveis em um lar próprio. Porém, isso não é o que acontece frequentemente. Vemos inúmeras pessoas morando na rua, com as condições humanas violadas, e várias extensões de terra ou muitos imóveis desocupados protagonistas da especulação imobiliária. Segundo o IBGE (2011) 9\% dos imóveis recenseados em 2010 estavam vagos, isto é, não possuíam morador na data de referência, neste caso em 31 de julho de 2010, e que poderiam abrigar as famílias brasileiras que não tem teto ou vivem em locais impróprios.

O processo de regularização fundiária exige muito mais do que observar e atender critérios de adequação, uma vez que não é tão fácil detectar que deverá ser feita a realocação de famílias que estão ocupando áreas que correm risco de desabamento nem remover comunidades imensas que estão em Áreas de Preservação Permanente (APP's), por exemplo. A realocação de famílias acarretará custos para o governo e alterará a vida dos integrantes que já têm um trabalho ou escola para seus filhos próximos. As remoções de assentamentos provocam impactos desastrosos na vida dos moradores. Dessa forma, é necessário que haja planejamento de programas sociais fundamentados na realidade brasileira que visem melhorar as condições de moradia e vida das famílias que residem em áreas irregulares e frágeis.

No decorrer dos anos, muitas políticas vêm sendo implementadas no intuito de avançar na regularização fundiária do Brasil, dentre elas podemos citar: a aprovação do Estatuto das Cidades, em 2001; a criação do Ministério das Cidades, em 2003; a aprovação da Lei № 11.977/2009, que aborda a regularização fundiária em assentos urbanos no Capítulo III; Lei no 12.424/2011, que modifica a Lei dos Registros Públicos no 6.015/1973, abordando tratamento específico para regularização fundiária em assentamentos urbanos; Lei n⿳o 12.651/2012, que possibilita a regularização fundiária em Áreas de Preservação Permanente.

Por meio destes instrumentos, é possível que a sociedade, em especial os municípios, atue com o objetivo de transformar as cidades. Ter terra regularizada é um direito da população urbana, cabe aos legitimados (que tem o poder de proceder com a regularização) participarem de forma ativa deste processo de ganho mútuo, pois ambos, município e famílias, terão diretos e deveres que proporcionarão a alteração e o crescimento das cidades. 


\section{Regularização fundiária como alternativa para melhoria habitacional}

A lei 11.977/2009 define regularização fundiária como o ato de incluir no contexto legal das cidades os assentamentos irregulares, através de medidas jurídicas, urbanísticas, ambientais e sociais, de modo que seja garantido o direito social à moradia aos ocupantes dessas áreas.

A Regularização Fundiária tem como objetivo assegurar a posse territorial à população, admitindo que haja a permanência das famílias de forma juridicamente correta, além de corrigir problemas ambientais e estruturais que comprometam a qualidade de vida da população e prever planejamento de ações de urbanização, colaborando para a redução das desigualdades sociais, através da inclusão dos indivíduos em ambiente propicie condições equilibradas de habitação e rompendo a impressão de que apenas as pessoas de alto poder aquisitivo podem está inseridas em um ambiente eficientemente harmônico.

Segundo o Ministério das Cidades (2009), mais de 13 milhões de domicílios brasileiros urbanos não são regulares, se compararmos com o número de domicílios particulares apresentado pelo o censo de 2010 do IBGE (2011), que é de 57.324.185, a irregularidade é equivalente a 22,68\%, percentual significativo de residências sem a devida titulação.

Porém, existem inúmeras formas de mudar esse quantitativo, já que havendo interesse de entes públicos ou privados para que seja efetivada a legalização da área, há vários instrumentos que podem ser utilizados para fins de regularização em áreas públicas e particulares.

De acordo com Barros (2014) para assentamentos públicos podem ser aplicados: a Concessão de Direito Real de Uso (CDRU), em que o município concede a utilização de terras de sua propriedade para fins específicos, de forma gratuita ou onerosa, para um terceiro; a Concessão de Uso Especial para Fins de Moradia (CUEM) é um direito subjetivo do indivíduo que ocupa área pública de até 250 metros quadrados para fins de moradia, de forma pacífica e ininterrupta por cinco anos, devendo ser emitida de forma gratuita e tendo validade permanente; Direito de Superfície, em que o proprietário urbano concede a outro indivíduo, o direito, temporário ou não, de utilizar sua propriedade, processo feito por meio de escritura pública registrada em cartório de imóveis; Cessão sob Regime de Aforamento, na qual ocorre a transferência de imóvel público por meio de carta de aforamento.

Já para áreas particulares, utilizam-se: Usucapião Judicial, que baseia-se na possibilidade de um bem ser usucapido, verificação de posse pacífica, mansa e contínua por determinado tempo de ocupação, definido de acordo com a modalidade utilizada e subdivide-se em Usucapião Especial Urbana Individual e Coletiva.

Portanto, cabe à sociedade buscar tornar a cidade legal, pois a regularização fundiária tem um princípio maior que garantir a segurança jurídica sobre a moradia: promover a implantação de equipamentos urbanos que visem reparar ou aprimorar as condições urbanísticas e sociais nas quais estão inseridos os moradores da cidade, especialmente, os da classe social mais fragilizada, proporcionando melhorias na qualidade de vida desses indivíduos e permitindo o crescimento planejado dos municípios, o que contribuirá para o desenvolvimento urbano nacional.

\section{Metodologia}

Constituiu-se um referencial teórico que apresenta o processo de construção e massificação urbana, destacando a formação dos ambientes destinados à habitabilidade, e a consequente desigualdade social presente nas cidades, que acarretam inúmeras mazelas para a sociedade e retardam o desenvolvimento citadino.

Para Vergara (2004), referencial teórico é uma apresentação de fundamentos relacionados ao tema em questão que tem como base publicações existentes a cerca do assunto que está em análise, possibilitando que o autor comente e argumente sobre conclusões auferidas por outros escritores.

Foi realizado um estudo multicaso em cidades do Semiárido Potiguar, por meio de análise do histórico de ocupação das áreas objeto de estudo e através de pesquisas cartorárias, que tiveram como 
objetivo verificar o índice de regularidade dominial de cinco cidades do Rio Grande do Norte: São Miguel, Venha-Ver, Luís Gomes, Encanto e Pau dos Ferros.

Para Gil (2001), estudo de caso é um instrumento que permite a análise do contexto real de um ou mais objetos, possibilitando a integração de sua descrição original. Para este trabalho, foram feitas análises de mais de um caso e, por esse motivo, denominamos pesquisa multicaso.

Além disso, foi realizado um processo investigatório nas prefeituras municipais de São Miguel, Venha-Ver, Luís Gomes e Encanto no intuito de identificar áreas que têm esses municípios como proprietários e mediante obtenção de informações dos cartórios e das prefeituras, realizou-se a vetorização dessas cidades e a demarcação dos bairros com matrículas em seus nomes.

Posteriormente, foram realizadas visitas aos assentamentos propriedade dessas cidades com a finalidade de levantar a quantidade de moradias existentes em cada bairro e colher depoimento dos moradores de aspectos relacionados ao tempo, forma de ocupação e regularização fundiária.

\section{Resultados e Discussões}

Como já foi explanado, a região Nordeste está marcada pela ocupação urbana desordenada que pode ser constatada ao se observar o elevado número de assentamentos subnormais existentes. Mediante esta situação o Ministério das Cidades vem procurando regularizar áreas de interesse social, promovendo a titulação de localidades de habitação para a população de baixa renda, especificamente no Rio Grande do Norte.

Grande parte dos municípios potiguares apresenta um quadro caótico em regularização fundiária, possuindo maior parte dos imóveis e extensões territoriais sem registro cartorário. Além disso, muitas das áreas que possuem titulação apresentam irregularidade no desmembramento, remembramento ou transferência de posse, pois há matrículas que representam mais de um lote, outras que expressam medidas incorretas e aquelas que não foram atualizadas após a venda do imóvel.

No que se refere às áreas municipais que são de uso popular, os moradores desses assentamentos, na maioria das vezes, dispõem de instrumentos defasados de concessão de uso ou não possuem nenhum instrumento jurídico que comprove sua posse ou autorização de utilização do ambiente que ocupam, isto é, estão incluídos no cenário de vulnerabilidade habitacional, visto que, "suas residências" não são propriamente suas, podendo ser reintegradas a qualquer momento.

Geralmente, um bairro inteiro, pertencente ao município, mas que é ocupado há muitos anos de forma mansa e pacífica, sem que a cidade tenha interesse em utilizá-la, possuindo registro em uma única matrícula, ou seja, devendo haver a divisão desta em várias, que designarão os lotes de cada residência e nomeará seus donos de acordo com as especificações dos terrenos a eles pertencentes.

A figura 2 mostra dois bairros que são de domínio municipal de São Miguel/RN: Nossa Senhora de Guadalupe e Tôta Barbosa, sendo o primeiro com estimativa de 164 residências e o segundo de 135 moradias, e que possuem apenas as matrículas das glebas, fazendo-se necessário efetuar o processo de Regularização Fundiária para tornar proprietários os moradores dessas áreas. 


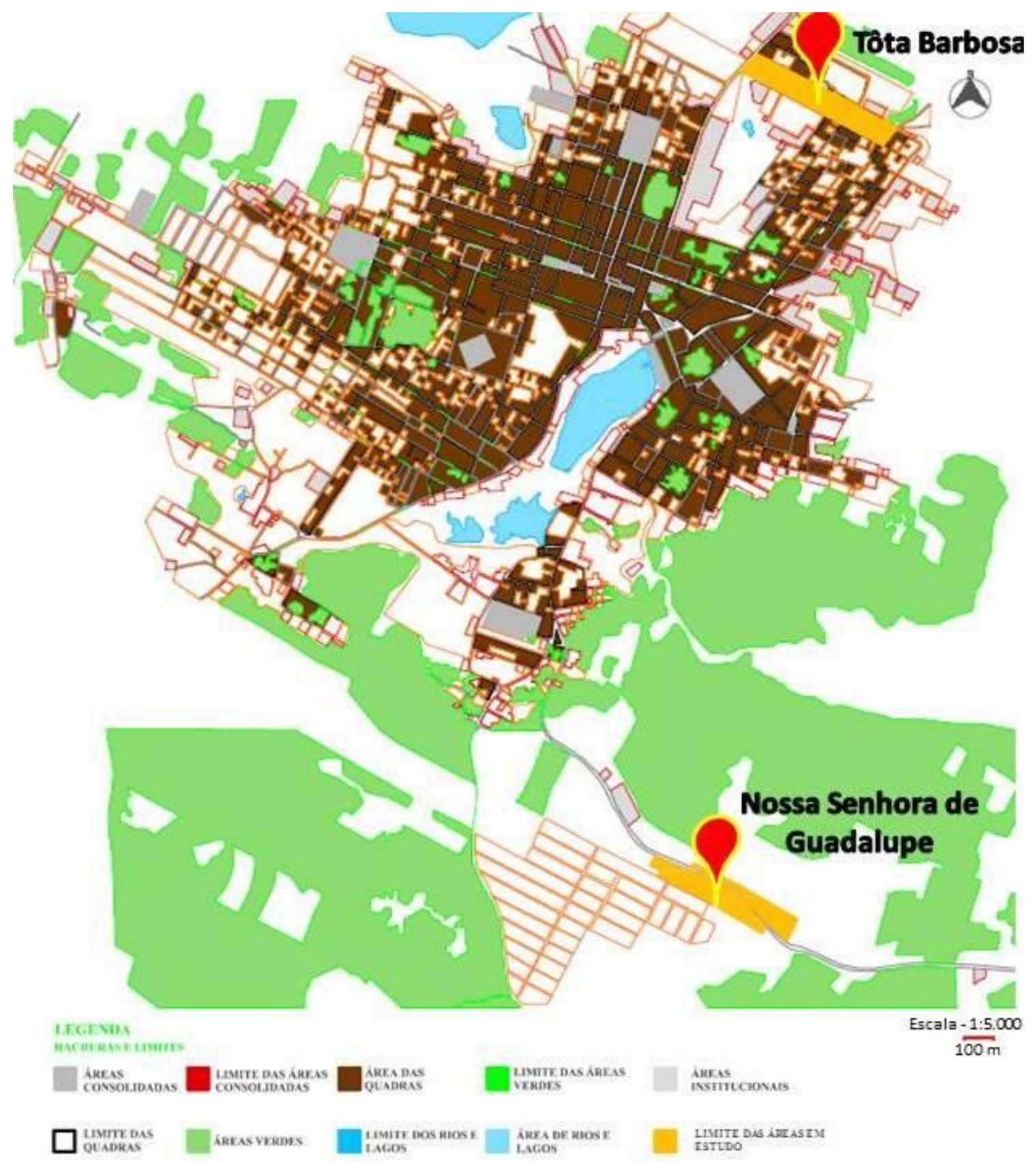

Figura 2 - Planta do Município de São Miguel/RN com identificação de áreas de dominialidade. Fonte: Autoria própria/projeto de pesquisa (2015).

Os ocupantes dessas áreas têm "cartas de aforamento" como direito de uso. No entanto, muitos dos documentos de autorização de utilização do bairro Tôta Barbosa já estão vencidas, visto que apresentavam um prazo de validade 20 anos. Os assentamentos foram ocupados de forma mansa e pacífica e não tiveram intervenção judicial.

Os bairros Bartolomeu, Frei Damião, Nossa Senhora do Perpétuo Socorro, Santo Expedito e parcela do Centro, são pertencentes a Venha-Ver/RN e estão registrados no cartório de imóveis em sua extensão total. A figura 3 refere-se ao Frei Damião. 


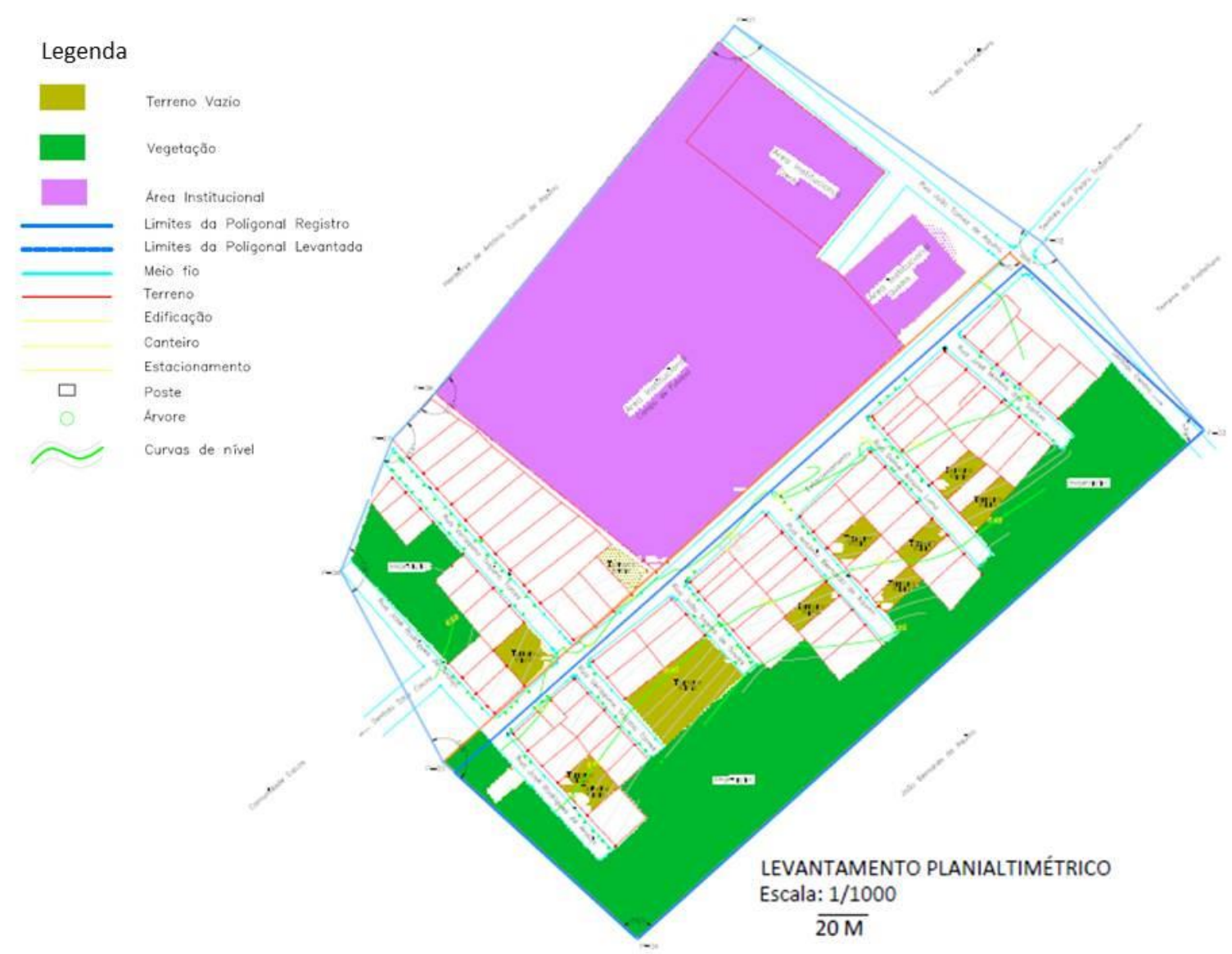

Figura 3 - Frei Damião, localizado em Venha-Ver/RN. Fonte: Autoria própria/projeto de pesquisa (2015).

Parte das residências desses bairros foram provenientes de programas habitacionais destinados à população carente. Todas as áreas que são de dominialidade municipal de Venha-Ver/RN não foram ocupadas por invasão ou de forma violenta. O quantitativo estimado de moradias presentes nos assentamentos de propriedade municipal é equivalente a 246. Os moradores das áreas demonstram interesse em adquirir a titulação de posse no intuito de adquirir recursos para melhorias habitacionais.

As áreas que fazem parte do patrimônio de Luís Gomes/RN e que abrigam em torno de 522 residências em sua extensão são: José Aquino de Lacerda (produto do Programa Minha Casa Minha Vida 1), São José, Guilhermão, Mirante e Sol Nascente.

Segundo informações cartorárias, há uma matrícula geral para o bairro José Aquino de Lacerda e Guilhermão, porém, para os assentamentos São José, Sol Nascente e parte do Mirante há um único registro. A figura 4 representa o assentamento urbano São José. 


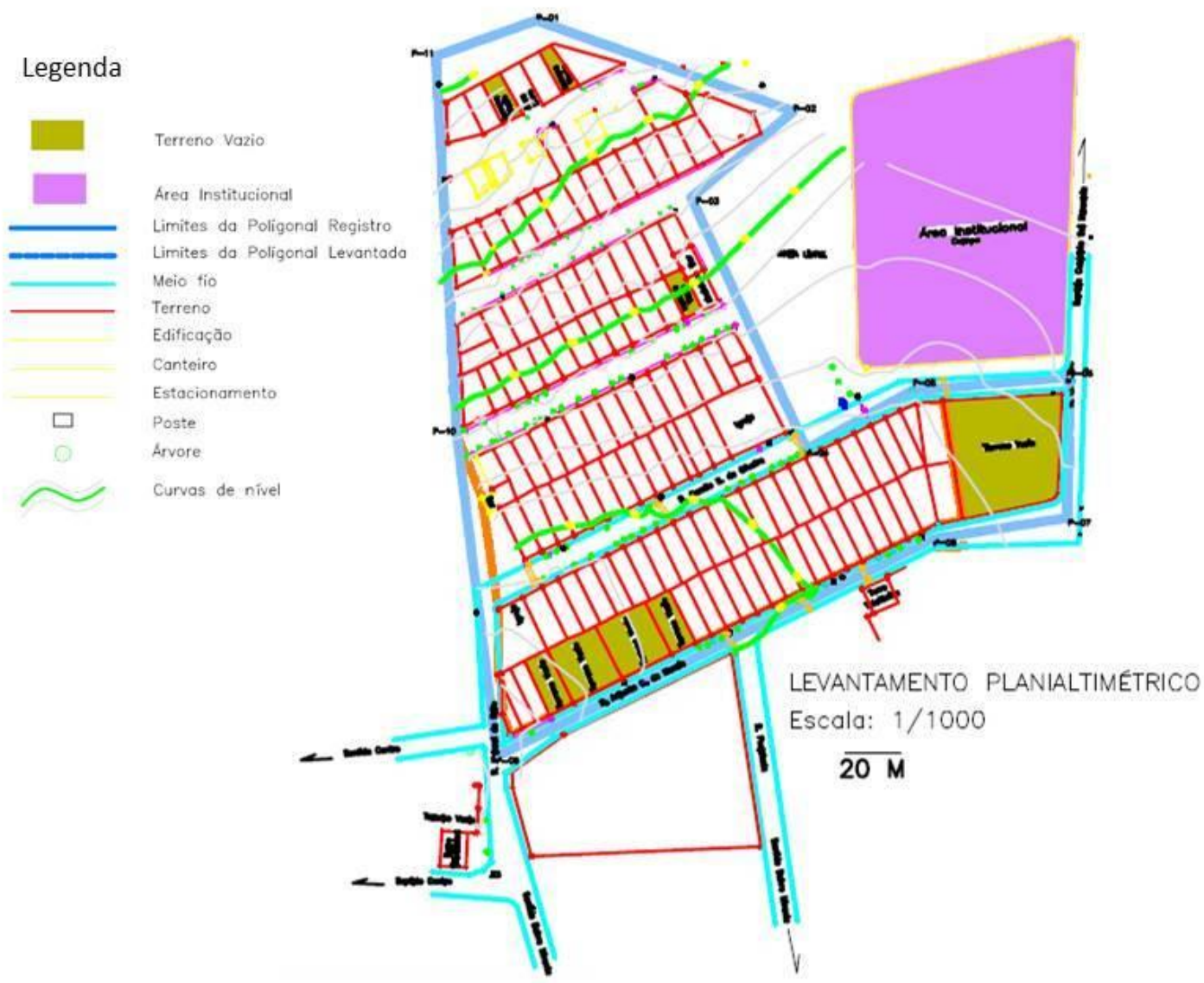

Figura 4 - Assentamento urbano São José - Luís Gomes/RN. Fonte: Autoria própria/projeto de pesquisa (2015).

A figura 5 deixa visíveis as áreas que a cidade de Encanto/RN afirma ser de sua propriedade. Elas compreendem: Antônio Cajazeiras, Novo Encanto, Osvaldo Januário e São Luiz. 


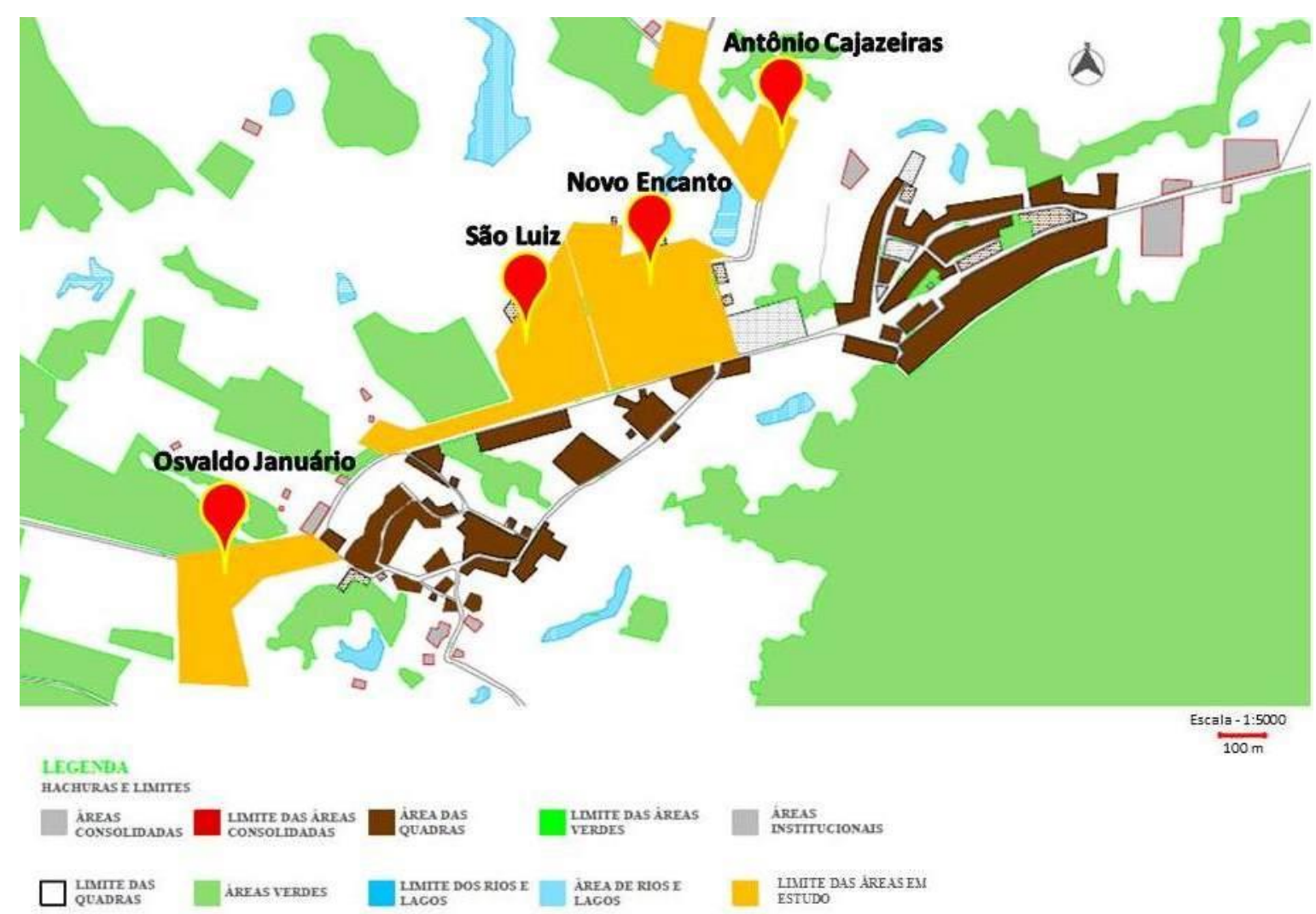

Figura 5 - Identificação de áreas de propriedade de Encanto/RN. Fonte: Autoria própria/projeto de pesquisa (2015).

O bairro Antônio Cajazeiras foi edificado por meio do Programa Minha Casa Minha Vida 1 e 2 e possui a escritura pública da área total em nome do município, adquirida através de desapropriação amigável, com indenização. No entanto, os demais assentamentos não têm registros na arquivologia do município e não foram encontrados pelo cartório de registro de imóveis da jurisdição responsável. No total, são aproximadamente 623 unidades habitacionais presentes em espaços de propriedade de Encanto/RN que não dispõem de registro cartorário.

Verifica-se que até as próprias áreas dos municípios não apresentam legalização no quesito regularização fundiária, uma vez que algumas possuem apenas o registro da área total e outras não têm nenhum tipo de documento que demonstre e confirme a quem pertence, o que comprova que há um alto índice de irregularidade fundiária no alto oeste potiguar.

Para realizar a regularização dessas áreas e garantir segurança para os moradores desses locais, os municípios podem optar por expedir um dos vários instrumentos possíveis, como por exemplo, CDRU, o aforamento, a CUEM ou a doação.

Porém, além das áreas municipais, o número de imóveis particulares que não dispõem de escritura pública é significativo e os motivos para este fator, segundo relatos de moradores dos municípios de São Miguel/RN e Venha-Ver/RN, são vários: falta de informação de como proceder no processo de regularização fundiária, burocracia e onerosidade para adquirir o título, tempo de espera para recebimento do documento de posse.

Em pesquisa feita aos cartórios de imóveis das cidades de São Miguel/RN, Venha Ver/RN, Luís Gomes/RN, Encanto/RN e Pau dos Ferros/RN, em janeiro de 2015, verificou-se que o número de registros imobiliários existentes nos municípios norte-rio-grandense é muito baixo. Os números estão mostrados na tabela 1. 
Tabela 1 - Quantidade de Imóveis Registrados em cinco municípios do Rio Grande do Norte em janeiro de 2015.

\begin{tabular}{cc}
\hline Cidade & $\begin{array}{c}\text { Quantidade de Imóveis } \\
\text { Registrados }\end{array}$ \\
\hline São Miguel & 1.073 \\
Venha-Ver & 54 \\
Luís Gomes & 1.476 \\
Encanto & 492 \\
Pau dos Ferros & 4.810 \\
\hline
\end{tabular}

Fonte: Autoria própria (2015).

Se compararmos a quantidade de imóveis registrados apenas com o número de domicílios existentes nestas cidades contabilizados pelo IBGE no censo de 2010, percebe-se que a taxa de regularização fundiária presente nestes municípios é muito baixa, pois a quantidade de domicílios permanentes nestas cidades é: 6.197 em São Miguel/RN, 932 em Venha-Ver, 2.604 em Luís Gomes, 1.479 em Encanto/RN e 8.023 em Pau dos Ferros/RN. Isto é, se analisarmos por esses números, o índice de regularização fundiária nos municípios citados são de 17,31\% em São Miguel, 5,8\% em Venha-Ver, 56,68\% em Luís Gomes, 33,27\% em Encanto, 59,95\% em Pau dos Ferros.

Dentre as citadas, a cidade que possui o maior percentual de registros imobiliários é Pau dos Ferros/RN. Porém, também há nos municípios imóveis registrados que não tem finalidade de moradia, ou seja, a quantidade de propriedades regularizadas, especialmente para fins de habitação ainda pode ter esse número inferior, o que torna o quadro mais preocupante, visto que sem a titulação de posse, não é possível comprovar quem é o indivíduo detentor da propriedade, além de haver a impossibilidade de programas de melhorias habitacionais financiados pelo governo, que requerem comprovação de posse.

Os municípios, especialmente a prefeitura, são os principais responsáveis pela realização de ações que visem regularizar ou apresentar soluções viáveis para disponibilizar condições de urbanização para áreas de ocupação irregulares, ilegais, situadas em APP's ou áreas de risco.

Analisando a situação atual, em que poucas áreas possuem escritura pública e, consequentemente seus moradores não têm segurança de posse de suas moradias, o Ministério das Cidades enxergou um caminho que fomentará de forma rápida e eficiente o processo de regularização no Semiárido Nordestino. Para isso, está em parceria com a Universidade Federal Rural do Semi-Árido, através do projeto "Programa Acesso à Terra Urbanizada", que conta com profissionais das áreas social, urbanística, topográfica, orçamentária e jurídica, e discentes de vários campus da universidade para que seja realizado o processo de regularização de áreas de 10 (dez) municípios do semiárido nordestino.

Diante dessa realidade, os municípios que o Ministério das Cidades selecionou para o desenvolvimento do projeto foram: Encanto, Venha-Ver, São Miguel, Carnaubais, Portalegre, Governador Dix-Sept-Rosado, Tibau, Janduís, Assú e Luís Gomes.

Serão selecionadas áreas prioritárias ocupadas pela população de baixa renda, caracterizadas como áreas interesse social, para a realização da regularização fundiária. Para ser beneficiado com a titulação o imóvel deve atender os critérios da lei 11.977/2009, no que diz respeito a: o possuidor deve ter área urbana de até duzentos e cinquenta metros quadrados há no mínimo cinco anos sem nenhuma reclamação judicial de posse, não ter direito de posse reconhecido em outro imóvel, ter baixa renda, ter o imóvel localizado em Zona Especial de Interesse Social e, se instalado em áreas públicas, que estas sejam declaradas de interesse social para implantação de projetos de regularização fundiária de interesse social.

Após a conclusão dos procedimentos de titulação, a realidade da população beneficiada mudará muito. A partir do momento que se tem o imóvel registrado o proprietário é assegurado do direito de sua moradia, é possível efetuar transferências de posse, adquirir financiamentos para reforma e 
construção, além de ter direito aos serviços públicos urbanos (saneamento básico, água, energia, pavimentação), tendo a cobrança do Imposto Predial e Territorial Urbano - IPTU de forma justa, já que todas as características da área ocupada estarão registradas no Cartório de Imóveis e cadastradas na prefeitura. Dessa forma, além de pagar o IPTU de acordo com as especificações imobiliárias, caso os serviços que devem ser fornecidos pelo município não estejam sendo prestados, poderão ser solicitadas pelas famílias, pois a quitação deste imposto deve ser revertida em benefícios para a população urbana.

\section{Considerações Finais}

O Brasil está acometido por consequências danosas da ocupação desordenada e sem planejamento. Em decorrência desse fator, muitas famílias apresentam condições altamente desfavoráveis para habitação, sujeitos a falta de serviços públicos e deficiência em saúde, educação, locomoção e outros fatores degradantes diretos ou indiretos.

O fato de o Nordeste ser marcado pela dificuldade financeira das famílias pode ser explicado, em parte, na enorme presença de assentamentos subnormais, visto que por não terem acesso monetário suficiente para adquirir domicílios localizados em áreas legais e que ofereçam condições adequadas para habitabilidade.

Mediante coleta de dados feita em registro de imóveis de algumas cidades do Rio Grande do Norte é possível verificar que o índice de regularização fundiária é baixo, um dos aspectos que deixa claro a falta de envolvimento dos municípios do estado no avanço da regularização fundiária das áreas irregulares.

Entretanto, o cenário urbano pode ser modificado no que diz respeito à regularizações de assentamentos e consequentemente acesso aos direitos inerentes aos ambientes urbanizados. Para isso, é necessário que a sociedade sinta-se envolvida na busca pela aquisição da titulação de posse ou se engaje em movimentos que lutem pela edificação de moradias que supram o déficit habitacional, que é tão grande no Brasil.

Com a regularização fundiária urbana, o ambiente é transformado e sua população poderá usufruir do verdadeiro direito à cidade. A ideia de que a formulação das cidades é impossível é uma percepção errônea, pois como diz Maricato. et al. (2013) se nosso mundo urbano foi imaginado e feito, então ele pode ser reimaginado e refeito.

\section{Referências}

Barros, F. M. P. (2014). Regularização Fundiária \& Direito à Moradia: Instrumentos Jurídicos e o Papel dos Municípios. Curitiba: Juruá.

Brasil (1988, 05 de outubro). Constituição da República Federativa do Brasil de 1988. Brasília: Diário Oficial da União.

(2009, 07 de julho). Lei 11.977, de 07 de julho de 2009. Dispõe sobre o Programa Minha Casa, Minha Vida - PMCMV e a regularização fundiária de assentamentos localizados em áreas urbanas; altera o Decreto-Lei oo 3.365, de 21 de junho de 1941, as Leis nos 4.380, de 21 de agosto de 1964, 6.015, de 31 de dezembro de 1973, 8.036, de 11 de maio de 1990, e 10.257, de 10 de julho de 2001, e a Medida Provisória no 2.197-43, de 24 de agosto de 2001; e dá outras providências. Brasília: Diário Oficial da União

Fundação Instituto de Pesquisas Econômicas - FIPE. (2014). Índice FIPEZAP de Preços de Imóveis Anunciados. Disponível em: <http://www.fipe.org.br/web/indices/fipezap/reseases/\%C3\%8Dndice\%20FipeZAP\%20\%20Divulga\%C3\%A7\%C3\%A3o\%20201411.pdf> Acesso em: 10 jun. 2015.

Gil, A. C. (2002). Como Elaborar um Projeto de Pesquisa. 4. Ed. São Paulo: Atlas. 
Instituto Brasileiro de Geografia e Estatística - IBGE. (2011). Vamos conhecer o Brasil. Disponível em: $<$ http://7a12.ibge.gov.br/vamos-conhecer-o-brasil/nosso-povo/caracteristicas-da-populacao $>$ Acesso em: 11 jun. 2015.

(2011). Sinopse do censo demográfico 2010. Disponível em:<http://www.ibge.gov.br/home/presidencia/noticias/imprensa/ppts/000000151648112020134801 05748802.pdf $>$. Acesso em: 11 jun. 2015.

(2011). Aglomerados subnormais Informações Territoriais. Disponível em: $<$ http://www.ibge.gov.br/home/presidencia/noticias/imprensa/ppts/000000151648112020134801057 48802.pdf $>$. Acesso em: 17 jun. 2015.

Maricato, E., Vainer, C., Harvey, D., Brito, F., Peschanski, J. A., Maior, J. L. S., Sakamoto, L., Secco, L., Iasi, M. S., Ninja, M., Davis, M., Movimento Passe Livre, Oliveira, P. R., Rolnik, R., Braga, R., Viana, S., Žižek, S., Lima, V. A. (2013). Cidades Rebeldes: Passe livre e as manifestações que tomaram conta do Brasil. São Paulo: Boitempo Editorial.

Ministério das Cidades. (2009). Regularização Fundiária Urbana no Brasil. Brasília.

Sindicato da Habitação - SECOVIRIO. (2014). Metro Quadrado da orla de Icaraí tem valor menor que a média de todo Rio. Disponível em:<http://www.secovirio.com.br/Noticias/Noticias/Metro-quadradoda-orla-de-Icarai-tem-valor-menor-do-que-a-media-de-todo-o-Rio-9094.html>. Acesso em: 17 jun. 2015.

Vergara, S. C. (2004). Projetos e Relatórios de Pesquisa em Administração. São Paulo: Atlas S. A. 